\title{
Codification of Business/Industrial Strategies by EFQM Model of Organizational Excellence
}

\author{
Firouzeh Javaheri Houshi* \\ M.A. of Business Management, Rasht Branch, Islamic Azad University, Rasht, Iran \\ ${ }^{*}$ Corresponding Author Email: Javahery_firoozeh@yahoo.com
}

Mohammad Taleghani

Department of Industrial Management, Rasht Branch, Islamic Azad University, Rasht, Iran

\author{
Doi:10.5901/mjss.2016.v7n2s1p511
}

\begin{abstract}
Spread the culture of organizational excellence and interest in the industry and service managers and experts to continuous improvement, leading to increased demand for the establishment of the EFQM system. The population of the research is the car pieceworkers companies that in this study, through this collection, those desired companies of car pieceworkers, which the number of them is 46 companies are selected which is a subset of the automaker's organization that is operator of EFQM. The study is practical based on objective, and in terms of data collection, is descriptive. Data for this study is of library method and examining documents from the automaker that is executive of EFQM has obtained which was the host of EFQM has achieved data through self-assessment by the process of obtaining the award. To analyze the data in this study, Pearson correlation test and regression have done by using SPSS software. The results show that all hypotheses are accepted.
\end{abstract}

Keywords: European Quality Management of Foundation, organizational excellence culture, the automobile industry.

\section{Introduction}

The quality issue is one of the main challenges for many organizations. One of the models for quality improvement in organizations is Excellence Model of Foundation for Quality Management in Europe.The EFQM Excellence Model Unlike other management approaches, with induction of integrated pattern of improvement in various aspects of the organization including human resources, leadership, processes and strategies, providing optimal product to our customers, guarantees employees and society (Asgharzadeh\& et al, 2014, P.2).Spread the culture of organizational excellence and managers and experts' favorites in the field of industry and services to continuous improvement, leading to increased demand for the establishment of the EFQM system.Identify enablers organizations and the results of the applying of structured approaches has known as modern management practices and organizations widely used of these models to identify strengths, areas of improvement and define the path of excellence (Dodangeh\&RosnahMohd, 2011). Marketing scholars and practitioners can interpret these results as helping to justify expenditures on brand and customer related marketing activities that create such long-term brand relationships with their consumers. (Taleghani et al., 2011) Organizational excellence models are efficient tools, if properly applied, can established organizational concepts and values, developing and implementing strategic plans, the use of self-assessment tools, organizational learning and continuous improvement in organizations and also be used to identify the best processes and provide optimum (Jolodari Mamghani, 2005, P.1).

\section{Problem Statement}

The main objective of human resource management in any organization, contributing to the better performance of the organization to achieve organizational goals and since performance evaluation, aware management of human resource needs of the organization, organizational culture and their attitude and makes possible to identify actions required to improve service quality and reduce costs; human resources management, to reduce problems, requires a model upon which their success rate in achieving the goals and business strategy, will be assessed and measured (MohammadpourZarandi\&Ghaderi, 2014, P.2).Spread the culture of organizational excellence and interest of managers to continuous improvement, leading to increased demand for Excellence System, that one of the most important models 
is Europe Foundation for Quality Management (EFQM) (Rodrigues and Alvarez, 2014).

EFQM Excellence Model as a basic framework to assess and improve organization has been introduced.A model that represents a sustainable advantage is that an excellence organization needs to achieve.While most organizations after evaluating this model in their organization, do not perform an essential step in improving organizational performance. In many organizations responsible for implementation, just to show work done in the organization, are doing self-assessment or ratings and finally, what can be seen in some organizations, is the centrality of the scoring and selfassessment.Although the scoring to assess progress seems to be necessary, but it should not be as targeted. The purpose of the evaluation is to improve organizational performance and that an organization be evaluated based on the EFQM model and has received considerable points, is an advantage over competing companies, but if it can reduced their weaknesses and rise their strengths based on the rate of this model, after diagnosis their strengths and weaknesses with the necessary way, is an important issue that is one of the most important topics in enforcement agencies of EFQM debates.

There are various theories on the relationship between the criteria, but each of these have examined this communications from an angle.Among these theories, Askyldsn 1 by integrating various theories proposed a model that is more comprehensive and more perfect; you can see the relationship in Figure 1 (Eskildsen\&Dahlgaad, 1999).

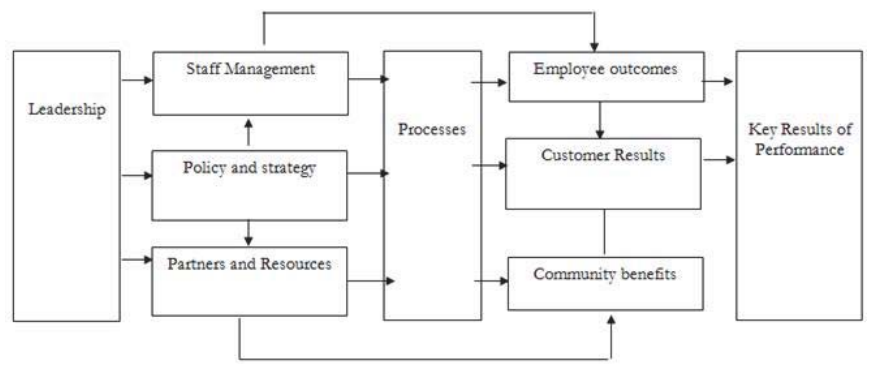

Figure 1. The causal model proposed by Eskildsen

Resource: Eskildsen, J.K \&Dahlgaad,J.J., (1999),."Focused Self-assessment usinf Flexible Weight"QMED Conference Proceeding

The main research question is "how can we test the relationship between the model criteria" and this is how to help automotive companies executive the EFQM by determining the relationship between criteria of model,to be considered more reasonable objectives and effective strategies in relation to its criteria.

This model is used in many Iranian organizations. But unfortunately, in most organizations focus on this model for the purpose of scoring, and self-assessment.Organizations, in the time of strategy formulation, after running the model, instead of according to the model criteria and to identify the main axes of the model, develop strategies based on the model implemented in the organization (Asgharzadeh\& et al, 2014, P.3).

This research has been done different from other researches and by using identifying and examines the relationship between criteria of the EFQM model ( 5 enabler criteria and four results criteria) and showing the intensity of this relationship, the main areas of this model can be shown in the applicable form in the automaker organizations that are executive of EFQM.

Among the various theories about the relationship between the criteria of the EFQM, the model of Eskildsenis more comprehensive and more detailed than other models, and has expressed the relationship between the criteria in the form of the proposed model and the theory. The intent of this research, is implementation of this proposed model in organization that are executive of EFQM, to prove this relationship through statistical methods in applicable form and accordingly develop the necessary strategies for the automaker executive EFQM. The main research question is that whether is there a significant relationship between the criteria of model or not?

\section{Literature Review}

Organization's excellence can be attributed to growth and improve in all its dimensions, so that with desired positions for all stakeholders and the balance between them, the probability of success in the long run increase (Atafar\& Frozen, 2013, P.89). Antony and Bhattacharyya (2010) known organizational excellence as the ability or capacity of one of the 
performance variables affecting on other organizational performance variables (Antony \& Bhattacharyya, 2010).Organizations are aware of the fact that organizational excellence is not a static goal and given the existing conditions and the changing needs of customers and all stakeholders, competitors' effort for the successful and new laws and regulations that are constantly changing, Cannot have a successful presence in national and international competition scenes by rely on traditional methods. The necessity of using models to provide assess the organization and identify strengths and areas for improvement for strategic planning is more tangible than ever. That's why the quality and efficiency efforts and attempts were made by experts, various patterns as organizational excellence models or create national quality awards and is considered one of the most common ways to achieve the above objectives, was used.These models are also known as self-assessment framework(Sharma, Talwar, 2007).

Self-assessment is a new phenomenon that now is used in western companies in order to identify problems and performance measurement.Senior managers of organizations believe that proposed evaluation system in the world such as the Baldrige Performance Excellence Model, European performance excellence model and model Deming among existing assessment models, including powerful tools evaluation (Arora, 1998, p.401).

Of course the starting for designing models for organizational performance excellence in research of Western experts on review of progress began in 1980 in Japan in the years after the war. In these researches, the main cause of low productivity and lack of competitiveness of industry in these countries compared to Japan was despite the National Quality Award in Japan and use them in order to stimulate competition and increase the ability of Japanese companies and Western countries were not taking advantage of this tool.Subsequently in 1987, Baldrige National Quality Award and European Quality Award in 1988, was designed. The quick move was welcomed by the European countries and other countries (Razani, 2002, P.26).

Thus, in terms of the increased global competition, technological innovations that occur rapidly, the change of process and constant changes in the economic, social and environmental conditions of the customer, the continue of this work will also hard.

In recognition of these challenges, the European Foundation for Quality Management (EFQM) was created to promote an approach to the management of European organizations that are posed on a global scale and guide them towards sustainable excellence. European Foundation for Quality Management is a non-profit organization in 1988 by fourteen valid European companies that was established with support from the Europe Union. Currently more than 800 companies in Europe are members of the organization (Kaplan RS, Norton, 2008).

The excellence fundamental concepts are those concepts that this model is built upon them. In fact, they are the foundation of this model. These concepts are derived from the core beliefs of the twentieth century's leading companies and organizations. These concepts include:
$>$ Result-oriented
$>$ Customer-oriented
$>$ Leadership and consistency in goals
$>$ Management by processes and facts
$>$ Development and employee involvement
$>$ Learning, innovation and continuous improvement
$>$ Development of trade cooperation
$>$ Corporate Social Responsibility

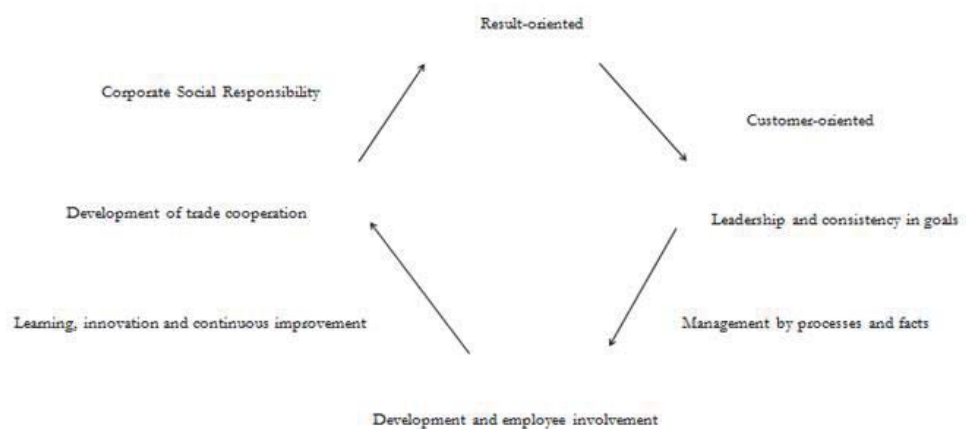

Figure 2. Fundamental concepts of EFQM 
Eight values and concepts in above comprise main base in the planning and deployment of systemsand to identify the situation of organization performance must use the criteria that are closely related to the above-mentioned concepts. The results include what the organization is acquired; in the excellent organization, the results have positive, good and lasting performance. Take appropriate targets and achieved it or are beyond. Good performance compared with others and to compete with it.Causal relationship between the approaches used and the results are clear. In addition, the results range covers the entire relevant area.Where it helps to understand and identify opportunities for improvement for example, the results are grouped according to customers and sections (Rezayatmandi\&Ghasemi, 2005, P.7).

\section{Hypotheses}

1. There is a significant relationship between the empowerment criteria and results criteria.

2. There is a significant relationship between the leadership criteria and criteria of policy and strategy.

3. There is a significant relationship between the leadership criteria and criteria of staff.

4. There is a significant relationship between the leadership criteria and criteria of partners and resources.

5. There is a significant relationship between criteria of policy and strategy andcriteria of staff.

6. There is a significant relationship between criteria of policy and strategy and criteria of partners and resources.

7. There is a significant relationship between criteria of policy and strategy and criteria of process.

8. There is a significant relationship between criteria of staffand criteria of staff results.

9. There is a significant relationship between criteria of staffandcriteria of process.

10. There is a significant relationship between criteria of partners and resources and criteria of society results.

11. There is a significant relationship between criteria of partners and resources and criteria of process.

12. There is a significant relationship between criteria of processand criteria of staff results.

13. There is a significant relationship between criteria of processand criteria of society results.

14. There is a significant relationship between criteria of processand criteria of customer results.

15. There is a significant relationship between criteria of staff results and criteria of key results of performance.

16. There is a significant relationship between criteria of staff results and criteria customer results.

17. There is a significant relationship between criteria of customer results and criteria of key results of performance.

18. There is a significant relationship between criteria of society results and criteria customer results.

\section{Previous Research}

Keshtkarand colleagues (2011) in a study to investigate the possibility of establishing criteria of Quality Management model of the European Foundation in the libraries of Medical Sciences of Tehran University based on demographic factors suggest thatthere is a significant difference Between the views of the staff of the three universities Medical Sciences of Irang Tehran, and ShahidBeheshti about the possibility of the establishment of the Quality Management model of European Foundation based on gender, position, majors, and educational degree. There are significant differences in the two components of partnerships and processes between the sexes, also in the components of results between opinions of managers and librarians managers showed significant differences,but there was no significant differences based on field of study.Finally by educational degree between their views in the each of the five components was a significant difference. Also Asgharzadeh and colleagues (2014) did a study entitled "Evaluation of the quality of services based on the European Excellence Foundation Quality Management Model EFQM in the University ofKashan University of Medical Sciences". They express in their study;there is the highest gap between current performance of faculty and student's expectations in the area of support services and consulting of students, management and quality of educational services. Using self-assessment based on the EFQM Model can be used as a tool for quality improvement in the higher education institutions.According to the alienation of higher education institutions with quality management and create the enabling environment is recommended that corrective actions of these institutions focused on infrastructure, including policies and procedures, processes and methods of performing services and supplies and equipment then extended to the processes of teaching - learning.To achieve and continue to improve the quality of the Commission with this title in medical universities as it seems necessary. Mohammad SadeghKhayatianYazdi with investigation as to design educational organizational excellence based on the EFQM model was followed, that identify the amount of importance of each criteria and sub-criteria of European model EFQM in the Imam Sadiq University. And it was concluded that in the excellence model of educational organizations based on the EFQM, a measure of leadership is more important and also through sub-criteria, the criteria formulation of mission, vision, values and ethics of leadership criteria is more important. 
Also Saeed Safari has done thesis titled evaluating the performance of the organization with a focus on indicators of management quality(Quality Awards) with DEA approach.In this study with reviewing models of organizational excellence identify Suitable criteria for evaluating the performance and organizational excellence and then this criteria and elements in the data envelopment analysis approach that further tangible using input and output to evaluate organizations, will be used.Rodriguez and Alvarez (2014) in a study titled "does the EFQM model identify and reinforce abilities using of information in an organization's to?" Concluded that the quality of information is directly affected of the resultsand when a company could be emphasized the quality of information, that have capacity and ability using of information. Establishment of Comprehensive quality management (TQM) and besides it the EFQM model in an organization can strengthen the capacity using of organization information (Rodriguez and Alvarez, 2014). A study entitled "profits of quality management" Gerqedt and his colleagues carried out in 2001, which this research says detailed discussion of ISO9000 and also EFQM model and the profits made from any of the methods(Gerqedt et al, 2001,pp.217-220). Also a study entitled: "The weight of the criteria of excellence model EFQM" by Esquildsenand Christiansen and Juhal conducted in 2001,that this research states detailed discussion regarding the cause and effect relationships between the two areas of empowerment and results (Esquildsen\& Christensen \&juhal, 2001, pp.183-95).

\section{Research Methodology}

The study based on objective, is practical and in terms of information collecting, is descriptive. In this study, data were collected by library method and by using documentsand by using SPSS software through regression and Pearson correlation are analyzed.Finally, by using the relationship between the variables and the tables and charts and hypotheses will be examined.

The population of the investigation is 64 companies of car pieceworkers, which are a subset of the EFQM operator automaker.

\section{Statistical Analysis and Hypothesis Testing}

\subsection{Descriptive analysis of research data}

Table 1. Descriptive statistics for variables

\begin{tabular}{lccccc} 
Variable & Minimum & Maximum & Average & Standard deviation & Number \\
\hline Leadership & 5 & 40.20 & 19.8239 & 6.84031 & 46 \\
Strategy and policy & 4 & 30.50 & 14.6591 & 5.75893 & 46 \\
human resources & 4.5 & 44.50 & 19.8054 & 7.30858 & 46 \\
Partners and Resources & 5 & 43.40 & 20.2354 & 7.18624 & 46 \\
Process & 15 & 70 & 34.9833 & 11.13739 & 46 \\
Human Resources results & 0 & 42.40 & 14.5302 & 8.65992 & 46 \\
Customer Results & 5 & 60.60 & 30.4174 & 14.62551 & 46 \\
Society Results & 0 & 15.10 & 5.9479 & 3.45845 & 46 \\
Key Performance Results & 5 & 60 & 31.3261 & 13.55068 & 46 \\
\hline
\end{tabular}

As shown in Table 1, the maximum and minimum points of subset of the automaker organizations that are presenter of the EFQM and average scores and standard deviations are visible.

\subsection{Deductive analysis of research data}

Table 2. The results of the correlation coefficient of research variables

\begin{tabular}{|c|c|c|c|c|c|c|c|c|c|c|c|}
\hline & $\begin{array}{l}\text { Society } \\
\text { Results }\end{array}$ & $\begin{array}{c}\text { Customer } \\
\text { Results }\end{array}$ & $\begin{array}{c}\text { Key } \\
\text { Performance } \\
\text { Results }\end{array}$ & $\begin{array}{l}\text { Human } \\
\text { Resources } \\
\text { Results }\end{array}$ & $\begin{array}{c}\text { The } \\
\text { Process }\end{array}$ & $\begin{array}{c}\text { Partners } \\
\text { and } \\
\text { Resources }\end{array}$ & $\begin{array}{c}\text { Human } \\
\text { Resources }\end{array}$ & $\begin{array}{l}\text { Strategy } \\
\text { and } \\
\text { Policy }\end{array}$ & Leadership & $\begin{array}{c}\text { Empowerment } \\
\text { Criteria }\end{array}$ & $\begin{array}{l}\text { Criteria } \\
\text { of } \\
\text { Results }\end{array}$ \\
\hline $\begin{array}{l}\text { Criteria of } \\
\text { Results }\end{array}$ & & & & & & & & & & .637 & \\
\hline $\begin{array}{l}\text { Society } \\
\text { Results }\end{array}$ & & .729 & & & .592 & .598 & & & & & \\
\hline Customer & .729 & & .764 & .716 & & & & & & & \\
\hline
\end{tabular}




\begin{tabular}{|c|c|c|c|c|c|c|c|c|c|c|}
\hline \multicolumn{11}{|l|}{ Results } \\
\hline $\begin{array}{l}\text { Key } \\
\text { Performance } \\
\text { Results }\end{array}$ & & .764 & & .620 & & & & & & \\
\hline $\begin{array}{l}\text { Human } \\
\text { Resources } \\
\text { Results }\end{array}$ & & .716 & .620 & . & .652 & .663 & & & & \\
\hline The Process & .592 & & & .652 & & .618 & .675 & .644 & & \\
\hline $\begin{array}{l}\text { Partners and } \\
\text { Resources }\end{array}$ & .598 & & & & .618 & & & .773 & .824 & \\
\hline $\begin{array}{l}\text { Human } \\
\text { resources }\end{array}$ & & & & .663 & .675 & & & .735 & .737 & \\
\hline $\begin{array}{l}\text { Strategy and } \\
\text { policy }\end{array}$ & & & & & .644 & .773 & .735 & & .878 & \\
\hline Leadership & & & & & & .824 & .737 & .878 & & \\
\hline $\begin{array}{l}\text { Empowerment } \\
\text { criteria }\end{array}$ & & & & & & & & & & .637 \\
\hline
\end{tabular}

Since the value obtained for all hypotheses Sig is zero and the value is less than 0.05 so we can say that $\mathrm{HO}$ rejectedand it can be concluded between all subsets of the presenter organization EFQM there is a significant relationship and the correlation between the variables in the above table is visible.

\section{Conclusions and Findings}

Since the amount of Sig for the relationship between all criteria in Subsets the Executer organization EFQM is zero and this amount is less than of $\alpha=0.05$ so we can say that $\mathrm{H} 0$ is rejected and there is a significant relationship between the criteria.As a result, we can say that all research hypotheses are confirmed.According to the first hypothesis can be said:With increasing what amount of the independent variable (empowerment criteria) will reach to an arbitrary amount of the dependent variable (results criteria).According to the second hypothesis can be said:Increasing what amount of the independent variable (leadership) will reach to the desired amount of the dependent variable (policy and strategy). The third hypothesis shows that with increasing what amount of the independent variable (leadership) will reach to an arbitrary amount of the dependent variable (human resources). This also applies about other hypotheses.According to the research findings and Confirmation of hypothesis have been developed recommendations as follows:According to the Fourth hypothesis this study indicates that there is a significant relationship between leadership criteria and policy criteria and strategy can provided the following suggestions:

Align the structure of the organization in the direction that makes the realization of policy and strategy.

- Ensuring a process that for developing and deploying and updating the policy and strategy in the organization, developed and has been executed.

$>$ According to the second hypothesis this study indicates that there is a significant relationship between leadership criteria and partnerscriteria and resources can provided the following suggestions:

- Meet, understand, and meet the needs and expectations

- creating organizational partnerships and participation in this work

- Appreciation of people and stakeholders groups for their loyalty and their role in the organization and business

$>$ According to the Sixthhypothesis this study indicates that there is a significant relationship between policy criteria and strategy partnerscriteria and resources can provided the following suggestions:

- $\quad$ balancing between partners' needs and expectations of short-term and long-term

- informing policy and strategy to partners and evaluating their awareness of the policy and strategy

$>$ According to the Seventeenthhypothesis this study indicates that there is a significant relationship between customer criteria and key results of performance criteria can provided the following suggestions:

- Goods and services have been designed and developed based on the needs and expectations of customers

- Contact with customer manage and enhanced.

\section{Suggestions for Future Research}

1- The impact of the implementation of the EFQM model on customer happiness

2- Comparing the results obtained of the implementation of the organizational Excellence Model EFQM with the results of other models of EFQM like Deming or Malcolm Baldrige, 
3- Measuring the impact of the implementation of the balanced scorecard approach (BSC) in points of organizational excellence by using the EFQM model

4- Measuring the impact of the implementation 5 s approach in Rating of organizational excellence by using the EFQM model

5- Assess the implementation of the EFQM model on the quality and price at Executer organization EFQM

6- Comparison of obtained results of implementation of the Skyldsen model in the car maker EFQM with the results of the implementation of the EFQM model in other industry and Executer organization

7- In the end can be recommended that this research have done through other statistical methods such as conventional methods (Knalykal) to assess the relations (cause-effect) between the criteria, different strategies and more accurate will be offered.

\section{Refrences}

Akbari H, Soltan M, Maleki A. Tehran: ArianaGhalam Press; 2008.p. 57-63.

Antony, J. Bhattacharyya, S. (2010), "Measuring organizational performance and organizational excellence of SMEs", Journal of Measuring Business Excellence, 14(2), 3-11.

Arora, K. C., (1998), "total Quality Management and ISo14000 sanjeer Kumar Kataria, Delhi".

Asgharzadeh, A.A., Meidani, Z., Gilasi, H.R., Maleki, M.R., \&NezadiNiasar, M., 2014, Evaluation of service quality based on the Excellence Model of European Foundation Quality Management EFQM at the Faculty of Kashan Medical Sciences, Development of education jundishapur: Spring 2014, Volume 5, Number 1. pp. 1-11.

Atafar, A., \&Forozan, B., 2013, investigating of FooladSepahan Esfahan's engineering company organizational Excellence based on Peters and Waterman model, Spring and Summer 2013, Volume 4, Number 1 (6), p.p.85-102.

Bondt, Bregjede, and zentner, Andrvej., (2007),"Quality Management in orthodontic practice" seminars in orthodontic, Vol.13 No.2.

Comison, cesar, (1996), "Total quality management in hospitality: an application of the EFQM model", Tourism management, Vol.17. No3.

Dodangeh J, RosnahMohd Y, 2011, A Decision Model for Selecting of Areas for Improvement in EFQM Model (November9,). 2011 IEEE International Conference onQuality and Reliability (ICQR), Bangkok, Thailand, September 14-17, Available from http://ssrn.com/ abstract=1957446:

Eskildsen, J.K \&Dahlgaad,J.J., (1999),;"“Focused Self-assessment usinf Flexible Weight"QMED Conference Proceeding.

Esquildsen, J. K. and Kristensen, K, and J uhl, H. J., (2001), "The criterion weights of the EFQM Excellence model", International Journal of quality \& Reliability management, Vol. 18 No. 8.

Geraedts, H.P.A and montenarie, R. and Van Rijk, P.P. (2001), "The benefits of total quality management" computerized medical Imaging and Graphics, No.25.

Go, M.F. and Gorers, R., (1998), " integrated quality for tourist destinations: a European perspective on achieving competitiveness", entree for Tourism management 21, published by Elsevier science Ltd.

JelodariMamghani, B., 2005, Organizational Excellence (EFQM), the first edition, Tehran: central publication of Research and Training of Iran Industrial.

Kaplan RS, Norton DP. Strategy maps: converting intangible assets in to tangible outcomes. 3th ed. Trans.

Keshtkar, Z., Shabani, A., Sadat, A., 2011, The possibility of establishing criteria of the European Foundation Quality Management model in the libraries of Tehran University of Medical Sciences based on demographic factors, Strides of Development in Medical Education: autumn and winter 2011, Volume 8, Number 2; P. Pp. 141-150.

Mohammadpoor, H., \&Ghaderi, J., 2014, assessment Organizational Excellence of Tehran Municipality based on the EFQM model, Economic and urban management. Volume 2, Number 7, p.p.1-13.

Razani, A.M., 2002, Familiar with EFQM model, the first edition, Tehran: MAM publication.

Razani, A.M., 2002, Familiar with the important models of organizational excellence, the first edition, Tehran: the MAM publication.

Razani, A.M., 2002, Self-assessment methods EFQM, The first edition, Tehran: MAM publication.

Rezayatmandi, A.L., \&Ghasemi, S., 2005, Tools of excellence (EFQM),(Second Edition), Tehran: publications of Science Institute for Barin researchers.

Rodríguez, Marta, Álvarez, M. Jesús. (2014). Does the EFQM Model Identify and Reinforce Information Capability? Journal of Social and Behavioral Sciences, vol 109, 716-721.

Sanches, Elena. And Lerona, Jon. and Gonzalez, Rose and Garcia, Marbella and Darpon, Jon and Josu, L. and GARAY,. (2005), "Adescrptive study of the implementation of the EFQM Excellence model and underlying tools in the Basque Heath service", imitational Journal for Quality in Heath care, Published by Oxford University.

Sharma, AK. Talwar, B. (2007), "Evolution of "universal business excellence model"incorporating Vedic philosoph", Journal of Measuring Business Excellence ,. 11 (3), 4-20.

Taleghani, Mohammad., Samadi Largani, Mahmood., Mousavian, Seyyed Javad. (2011). "The Investigation And Analysis Impact Of Brand Dimensions On Services Quality And Customers Satisfaction In New Enterprises Of Iran", Contemporary Marketing Review, Vol. 1(6) pp. $01-13$. 